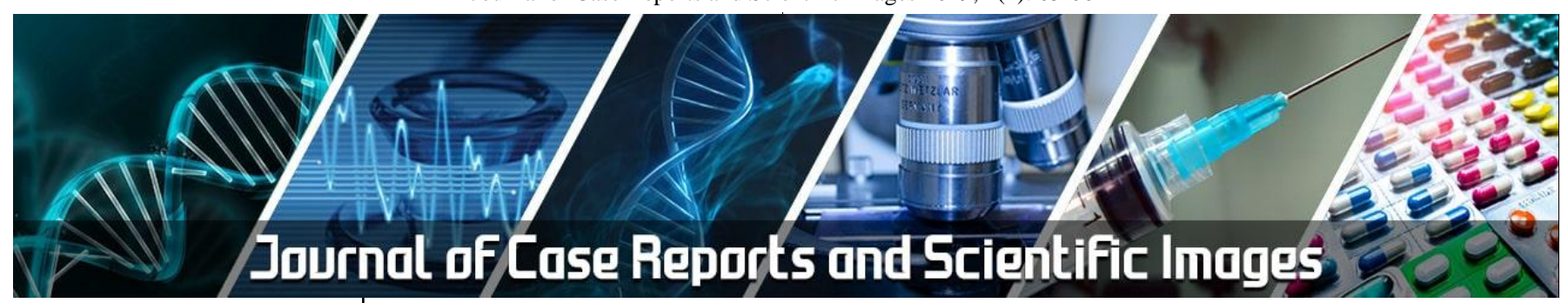

E-ISSN: 2708-0064 P-ISSN: 2708-0056 www.allcasereports.com JCRSI 2019; 1(1): 05-06 Received: 09-11-2018 Accepted: 11-12-2018

Mostafa Aslani

Department of Scientific, Iran University of Science and Technology, Tehran, Iran
Corresponding Author: Mostafa Aslani Department of Scientific, Iran University of Science and Technology, Tehran, Iran

\section{Deviated nasal septum in 27 years old female managed with endoscopic septoplasty}

\section{Mostafa Aslani}

DOI: https://doi.org/10.33545/27080056.2019.v1.i1a.3

\begin{abstract}
Deviated nasal septum is frequent finding. Deviated nasal septum may cause nasal obstruction and predispose to various inter-related ailments. The diagnosis of septal deviation can be established based on clinical symptoms, physical examination or investigation. We managed the case of DNS with septoplasty.
\end{abstract}

Keywords: Deviated nasal septum, Nasal obstruction, Septoplasty

\section{Introduction}

Though majority of human beings have deviated nasal septum, most of them are asymptomatic and cause little if any discomfort. However, deviated nasal septum may cause nasal obstruction and predispose to various inter-related ailments like sinusitis, epistaxis, dysfunction of the Eustachian tube, otitis media, and respiratory tract infections both upper and lower, dental mal-alignments and in turn poor general health. Deviation of the septum was classified by Cottle into four different groups: subluxation, large spurs, caudal deflection and tension septum. Septoplasty is one of the surgical procedures for the correction of a deviated nasal septum.

The management of septum deviation is highly dependent on the complaints and complications and in some cases an operative procedure is required to correct the septum deviation to improve the function of the nose as well as for esthetic purposes. Septoplasty is a surgical procedure to alter the shape or position of a crooked septum by repairs its cartilaginous and bony part. Conventional septoplasty is performed under surgeon's bare eyes and headlights guidance that can give a poor visualization. The operator often had difficulty in evaluating the most severe part of the septum deviation. It also result in excessive bone resection making it difficult to revise. Currently, however, septoplasty has been done under endoscopy guidance. We reported a case of DNS who has undergone endoscopic septoplasty.

\section{Case report}

A 27 years old female visited to ENT department with nasal congestion since 2.5 years. Patient also complains of frequent colds and headaches and difficulty in smells. All vital signs were within normal limits.

ENT examination was done and both sides of nasal cavity were narrow; the mucosa was normal. There were inferior turbine hypertrophy and deviation of nasal septum to the left side. Nasoendoscopic examination confirmed that findings. A CT scan was performed which showed nasal septum deviation and inferior turbines hypertrophy.

We planned endoscopic septoplasty under general anesthesia. After the procedure, splint then attached to both sides of septum and anterior tampon was also applied on both sides of the nose that was maintained for 2 days. The patient was given antibiotic cefotaxime 1 gram twice daily (IV) and ketorolac $30 \mathrm{mg}$ every 8 hours (IV). No complication found and outpatient care was given. The patient had no complain and on the anterior rhinoscopy appears normal. Prognosis of patient was good.

\section{Discussion}

Beauty of the face is related to the balance and symmetry of different parts of the face which 
includes the nose. The face loses its beauty if the balanced nose is not in harmony with the other components of the face ${ }^{[5]}$. Deviated nasal septum (DNS) is a rule rather than an exception and is considered to arise out of consequence of trauma either during intra-uterine life or thereafter. Nasal septal deviations play a critical role in nasal obstruction symptoms, aesthetic appearance of the nose, increased nasal resistance, and sometimes snoring. Consequently, a comprehensive assessment of the nasal septum serves an essential role in preoperative planning, reestablishing function, and overall cosmetic appeal. Typically, a septoplasty suffices in addressing significant nasal septal deviations, but on occasion such deviations warrant a singlestage septorhinoplasty ${ }^{[6]}$. We reported a case of DNS who has undergone endoscopic septoplasty.

Parrilla et al. ${ }^{[7]}$ highlighted the importance in considering the anatomy behind the deviation and how preoperative nasal septal analysis guides the preoperative assessment and plan as well as operative technique, reducing the risk of complication and repeat surgery which in themselves present with cumbersome challenges.

Sood et al. ${ }^{[8]}$ found that age group 10-20 years had 25, 2030 years had 18, 30-40 years had 15 and $>40$ years had 10 patients. The difference was significant $(\mathrm{P}<0.05)$. Right internal nasal valve angle (RINVA) was 10.81 degree, Left internal nasal valve angle (LINVA) was 9.92 degree, Left external nasal base area (LENBA) was 1.13 degree, right external nasal base area (RENBA) was 1.16 degree, Left internal nasal valve area (LINVAr) was 0.43 degree and Right internal nasal valve area (RINVAr) was 0.45 degree. Authors found that CT scan is useful in assessment of cases of septoplasty in adults.

Khan et al. ${ }^{[9]}$ conducted a study among 115 cases of DNS for a period of one year. While detailed clinical study was done in 115 cases, surgery was performed in 60 cases. They were divided into group A and group B with 30 cases in each group. Conventional septoplasty was performed in group A while endoscopic septoplasty in group B. The male to female ratio was found to be $2.19: 1$. Majority (37.18\%) patients were of age group 11-20 years with deviation to the left $(54.78 \%)$. Nasal obstruction (58.26\%) was the commonest presenting complaint. Postoperatively, a significant relief of symptoms was observed in endoscopic septoplasty in terms of nasal obstruction (93.33\%) and hyposmia (87.5\%). Post-operative complications were higher in conventional septoplasty with significant rate of residual deviation.

Teixeira et al. ${ }^{[10]}$ review ascertained that the majority of the currently published classification systems for internal nasal septal deviations can be summarized by C-shaped or reverse C-shaped, as well as S-shaped or reverse Sshaped deviations in the anteroposterior and cephalocaudal dimensions. For imaging studies, predefined points have been defined along the septum. Common terminology can facilitate future research.

\section{Conclusion}

The diagnosis of septal deviation can be established based on clinical symptoms, physical examination or investigation. We managed the case of DNS with septoplasty.

\section{References}

1. Jain L, Jain M, Chouhan AN, Harshwardhan R. Conventional Septoplasty verses Endoscopic Septoplasty: A Comparative Study People's J Scientific Research. 2011, 4(2).

2. Gupta N. Endoscopic septoplasty. IJOHNS. 2005; 57(3):240-3.

3. Ranjan GA, Rahul G, Jayman R Endoscopic Septoplasty; A novel technique-A case series of 19 cases. Clin Rhinol. 2009; 2(3):11-3.

4. Min YG, Jung HW, Kim CS. Prevalence study of nasal septal deformities in Korea: results of nation-wide survey. Rhinol. 1995; 33(2):61-5.

5. Sinha SN, Maheshwari VK. Clinical and Anatomical Study of deviated nasal septum. Indian J Otolaryngol. 1970; 22(4):204-9.

6. Daghistani KJ. Nasal Septal Deviation in Saudi Patients: A Hospital Based Study J KAU Med Sci. 2002; 10:39-46 (1422 AH).

7. Parrilla, Artuso A, Gallus R, Galli J, Paludetti G. The role of septal surgery in cosmetic rhinoplasty," Acta Otorhinolaryngologica Italica 2013; 33 (3):146-153.

8. Sood A, Tiwari S. Assessment of septoplasty patients with the help of CT scan - A clinical study. J Adv Med Dent Scie Res. 2019; 7(9):47-50.

9. Khan MN, Nath K, Uddin S. A clinical study of deviated nasal septum with special reference to conventional and endoscopic septoplasty. Int J Res Med Sci. 2016; 4:5165-71.

10. Teixeira J, Certal V, Chang ET, Camacho M. Nasal septal deviations: a systematic review of classification systems. Plastic surgery international, 2016. 